Gut, 1985, 26, 1179-1182

\title{
Serum pepsinogens I and II and gastric mucosal histology after partial gastrectomy
}

\author{
P SIPPONEN, I M SAMLOFF, M SAUKKONEN, AND K VARIS
}

From the Department of Pathology, Jorvi Hospital, Espoo, Finland; Research Service, Veterans Administration Medical Center, Sepulveda, and Department of Medicine, UCLA School of Medicine, Los Angeles, California; and Second Department of Medicine, University of Helsinki, Finland

SUMMARY We determined the effect of postgastrectomy gastritis on serum pepsinogen I and pepsinogen II concentrations in 108 subjects with subtotal gastric resection. Eleven had normal remnant mucosa, 22 had superficial gastritis, and 75 had atrophic gastritis. In the subjects with superficial gastritis, serum pepsinogen I and II concentrations were significantly higher than in those with normal remnant mucosa, but the ratio of pepsinogen I to II did not differ from normal. In atrophic gastritis, serum pepsinogen I concentrations fell with increasing severity of mucosal damage, but pepsinogen II was persistently raised. Consequently, the ratio of pepsinogen I to II in subjects with atrophic gastritis was significantly lower than in those with superficial gastritis or normal remnant mucosa. Discriminant function analysis revealed that the ratio of pepsinogen I to II, in combination with the absolute level of pepsinogen II, had a sensitivity of $80 \%$, a specificity of $73 \%$, and a positive predictive value of $87 \%$ for atrophic gastritis in this population. We propose that the parallel increase in serum pepsinogen I and II concentrations in postgastrectomy superficial gastritis is because of an increased rate of endocrine release of both zymogens from the fundic glands, and that the dichotomy in pepsinogen I and II concentrations in postgastrectomy atrophic gastritis results from the loss of fundic glands, which produce both zymogens, and the appearance of metaplastic pyloric glands, which produce only pepsinogen II.

Partial gastric resection for duodenal ulcer is followed by a high prevalence of atrophic gastritis of the remnant mucosa. ${ }^{1-4}$ This is associated with an increased risk for gastric cancer, ${ }^{4}$ while the absence of atrophy may be associated with an increased risk for recurrent ulcer. ${ }^{5}$ Postsurgical atrophy, unlike atrophic fundic gland gastritis in the general population, is not associated with a high serum gastrin or with circulating antibodies to parietal cells. ${ }^{2}$ Thus, the presence of postoperative atrophic gastritis can be ascertained only by gastric biopsy or acid secretory tests.

Atrophic fundal gastritis in unoperated subjects has been found recently to be associated with a raised concentration of serum pepsinogen II (PG II) and a low concentration of pepsinogen I (PG I). ${ }^{6}$ These findings appear to reflect two morphological phenomena of atrophic gastritis, namely the loss of

Address for correspondence: Pentti Sipponen, MD, Department of Pathology, Jorvi Hospital, 02740 Espoo 74, Finland.

Received for publication 3 December 1984 fundic glands, which secrete PG I and PG II, ${ }^{78}$ and their replacement by metaplastic pyloric glands, which produce only PG II. ${ }^{89}$ Because of the discordant behaviour of PG I and PG II, the ratio of PG I to PG II in serum has been found to be a marker of atrophic gastritis in unoperated subjects. ${ }^{6}$ In this study, we have investigated the possibility that serum PG I and PG II concentrations might also serve as a subclinical marker of atrophic gastritis in patients with partial gastric resection.

\section{Methods}

\section{SUBJECTS}

The study population consisted of 108 men who had participated in an endoscopic biopsy study of the prevalence of gastritis after partial gastric resection and Billroth II anastamosis for duodenal ulcer. The morphologic characteristics of the gastric remnant mucosa have been reported previously. ${ }^{2}$ Briefly, biopsy specimens were obtained at endoscopy from 
the anterior and posterior walls of the gastric remnant, processed for light microscopy, and classified as normal, superficial gastritis, or mild, moderate, or severe atrophic gastritis. Each subject was assigned a histologic diagnosis based on the average score of all biopsies or if two categories were represented equally, to the more severe. There were 11 subjects with normal mucosa, 22 with superficial gastritis, and 75 with atrophic gastritis. The degree of atrophic gastritis was mild in 46 subjects, moderate in 25 , and severe in four.

The interval between operation and study ranged between two and 20 years. The mean ( \pm SD) age of the subjects was $50 \pm 9$ years. None had clinical symptoms of recurrent ulcer and none was found to have an ulcer at endoscopy. Each subject had consented to the study after its nature and purpose had been explained.

\section{SERUM PEPSINOGENS}

The concentrations of PG I and PG II in serum were determined by radioimmunoassay as described previously, ${ }^{10}$ without knowledge of the biopsy results.

\section{STATISTICAL ANALYSIS}

The test results were normalised by square root transformation. Discriminant values were generated by computer using established programs $\mathrm{s}^{11} 12$ and used to determine the expressions of PG I and PG II that best distinguished subjects with atrophic gastritis from those with normal remnant mucosa or superficial gastritis. The significance of differences in mean values was determined by Student's $t$ test for unpaired samples.

\section{Results}

The mean $( \pm$ SE) concentrations of serum PG I and PG II were $27 \cdot 6 \pm 4 \cdot 2$ and $9 \cdot 3 \pm 1 \cdot 3 \mu \mathrm{g} / 1$, respectively, in the subjects with normal mucosa in the gastric remnant (Fig. 1).

In the subjects with superficial gastritis, serum PG I was $46 \cdot 0 \pm 4 \cdot 4 \mu \mathrm{g} / \mathrm{l}$ and serum PG II was $15 \cdot 2 \pm 1 \cdot 3$ $\mu \mathrm{g} / \mathrm{l}$ (Fig. 1). Both values were significantly higher than in the group with normal mucosa. The PG I/PG II ratio, however, did not differ from normal (Fig. 2 ), because the percentage increments of PG I and PG II were similar, about $65 \%$.

The mean concentration of serum PG I in the subjects with atrophic gastritis decreased progressively with increasing severity of mucosal damage. The values were $36 \cdot 2 \pm 3 \cdot 0,25 \cdot 8 \pm 3 \cdot 9$, and $14 \cdot 7 \pm 2 \cdot 4$ $\mu \mathrm{g} / \mathrm{l}$, respectively, in subjects with mild, moderate, and severe involvement (Fig. 1). In contrast, serum PG II concentrations were significantly raised in each histologic category and were not related to the

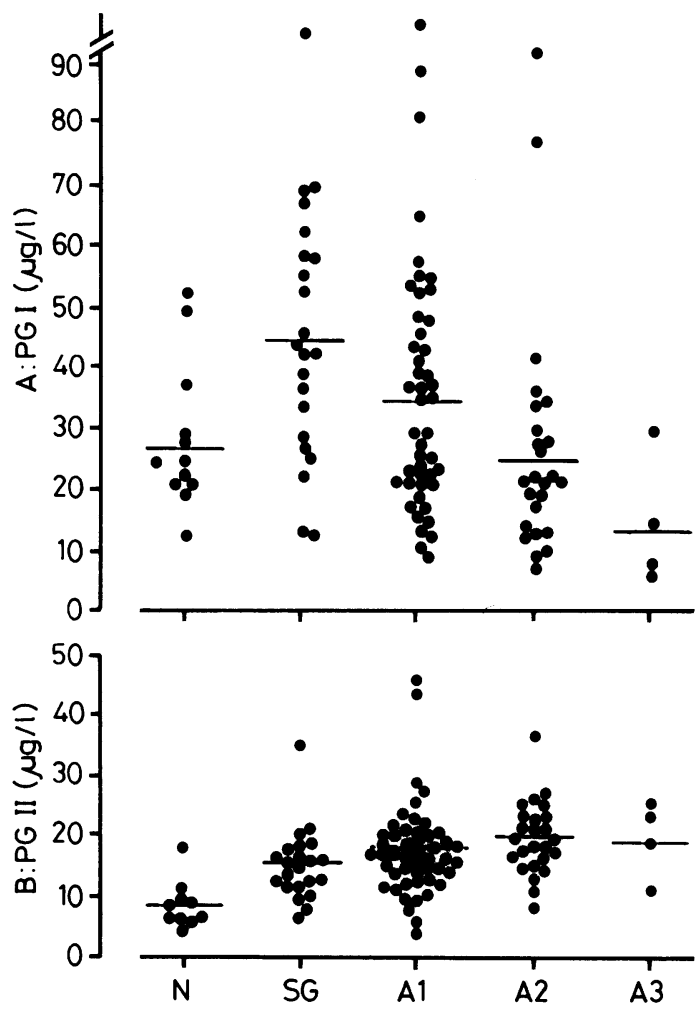

Fig. 1 Distribution of serum levels of pepsinogen I $(A)$ and pepsinogen $I I(B)$ according to the histological status of the remnant mucosa. $\mathrm{N}$, normal body mucosa; SG, superficial gastritis; $\mathrm{A} 1, \mathrm{~A} 2$, and $\mathrm{A} 3$, mild, moderate or severe atrophic gastritis, respectively.

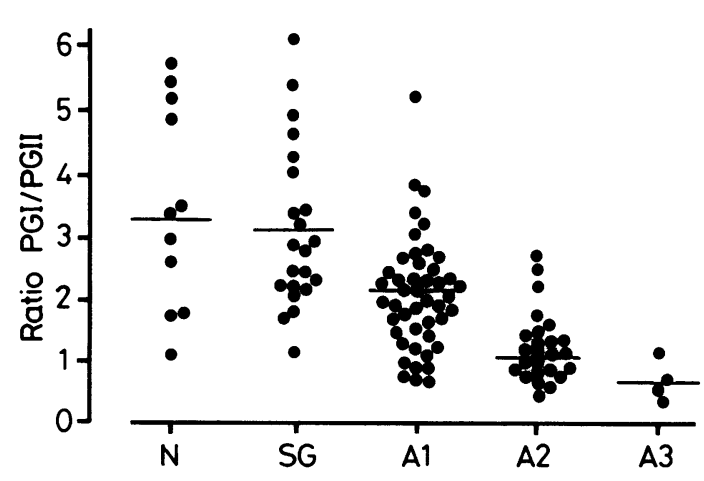

Fig. 2 Distribution of values for the pepsinogen I to pepsinogen II ratio according to the histological status of the remnant mucosa. For abbreviations, see Fig. 1. 
severity of mucosal damage. The values, in order of increasing severity of atrophic gastritis, were $17 \cdot 8 \pm 1 \cdot 2,19 \cdot 8 \pm 1 \cdot 2$, and $18 \cdot 4 \pm 3 \cdot 1 \mu \mathrm{g} / \mathrm{l}$ (Fig. 1). Thus, owing to the progressive fall in serum PG I and the persistent rise of serum PG II, the PG I/PG II ratio was also inversely related to the severity of mucosal damage. The ratio was $2 \cdot 13 \pm 0.13$ in subjects with mild involvement, $1 \cdot 22 \pm 0 \cdot 11$ in those with moderate involvement, and $0 \cdot 80 \pm 0 \cdot 13$ in those with severe atrophic gastritis (Fig. 2). The ratio in all subjects with atrophic gastritis was $1 \cdot 74 \pm 0 \cdot 11$, significantly less $(p<0.01)$ than the value of $3 \cdot 17 \pm 0.29$ in the subjects with normal mucosa or superficial gastritis.

Discriminant function analysis revealed that the PG I/PG II ratio in combination with the absolute level of PG II was better able to identify subjects with atrophic gastritis than either the ratio or the level of PG II alone. The discriminant value for this combination had a sensitivity of $80 \%$, a specificity of $73 \%$, and a positive predictive value of $87 \%$ for atrophic gastritis of the gastric remnant (Table).

\section{Discussion}

This study has shown that in subjects with partial gastric resection, increasing severity of atrophic gastritis of the remnant mucosa is associated with a progressive fall in serum PG I and with a persistent rise of serum PG II. These findings are similar to those observed in unoperated subjects with atrophic gastritis of the fundic gland mucosa ${ }^{6}$ and can be explained by the morphologic features of this disorder - a loss of chief cells, which secrete both PG I and PG $\mathrm{II}^{78}$ and the appearance of metaplastic pyloric glands which produce only PG II. ${ }^{89}$

Because there is no reason to suspect that gastritis alters the metabolic clearance rates of PG I and PG

Table Classification matrix of gastric mucosal histology by pepsinogen I/pepsinogen II ratio in combination with pepsinogen II

\begin{tabular}{|c|c|c|c|}
\hline \multirow[b]{2}{*}{$\begin{array}{l}\text { Classification } \\
\text { by biopsy }\end{array}$} & \multirow[b]{2}{*}{$\begin{array}{l}\text { Subjects } \\
\text { (no) }\end{array}$} & \multicolumn{2}{|c|}{$\begin{array}{l}\text { Classification by } P G \\
I / P G I I \text { ratio and } P G I I^{*}\end{array}$} \\
\hline & & $\begin{array}{l}\text { Normal or } \\
\text { superficial } \\
\text { gastritis }\end{array}$ & $\begin{array}{l}\text { Atrophic } \\
\text { gastritis }\end{array}$ \\
\hline $\begin{array}{l}\text { Normal or } \\
\text { superficial gastritis }\end{array}$ & 33 & 24 & 9 \\
\hline Atrophic gastritis & 75 & 15 & 60 \\
\hline
\end{tabular}

Sensitivity: $60 / 75=0 \cdot 80$; specificity: $24 / 33=0 \cdot 73$; positive

predictive value: $60 / 69=0.87$

${ }^{*}$ Discriminant value:

$\sqrt{\text { PG I/PG II }}-0 \cdot 22 \sqrt{\text { PG II }}<0.646$.
II, it is reasonable to assume that the observed alterations in serum PG I and PG II concentrations reflect changes in their rates of entry into the circulation. Thus, the significant rises in serum PG I and PG II that were found in the subjects with superficial gastritis implies that inflammation of the gastric mucosa causes an increased rate of release of PG I and PG II into the circulation. Hyperpepsinogenaemia and increased urinary pepsinogen excretion have been reported previously in subjects with superficial gastritis. ${ }^{6}{ }^{13-15}$ It is of interest that in this study, which included only subjects with antral resection, serum PG I and PG II concentrations rose in parallel, while in a previous study of unoperated subjects, superficial gastritis was found to result in a greater percentage rise of PG II than PG I. ${ }^{6}$ Because in the latter study superficial gastritis of the fundic gland mucosa was almost always associated with antral gastritis, it seems reasonable to propose that the 'excess' PG II in the unoperated subjects was derived from an increased rate of endocrine release of PG II from the pyloric glands in the gastric antrum. An alternative possibility, that there was a relative increase in the rate of release of PG II from the fundic glands, is not supported by the results of this study.

The data in postoperative superficial and atrophic gastritis also suggest that the relative concentrations of PG I and PG II in serum reflect their respective cell masses, while their absolute levels reflect both their cell masses and the presence of mucosal inflammation. This proposal would explain the finding that the mean serum PG I concentration in the subjects with mild atrophic gastritis was intermediate between those found in subjects with normal remnant mucosa and superficial gastritis. Mucosal inflammation is common to superficial gastritis and mild atrophic gastritis, but only the latter is characterised by a partial loss of fundic glands. Thus, the lower serum PG I concentration in mild atrophic gastritis, relative to that in superficial gastritis can be explained by a loss of chief cells. Similarly, the higher serum PG I concentration in mild atrophic gastritis, relative to that found in subjects with normal remnant mucosa, can be explained by an increased rate of release of PG I from a smaller chief cell mass.

It should be noted that a lack of correlation has also been reported between the parietal cell mass and gastric acid output in unoperated subjects with superficial gastritis. ${ }^{314}$ In this instance, the discordance between structure and function is the converse of that found for serum pepsinogen concentrations - marked hypochlorhydria or achlorhydria in the presence of normal appearing parietal cells. The practical utility of these observations is that the 
serum PG I concentration can readily distinguish patients with achlorhydria caused by superficial gastritis from those with achlorhydria caused by severe atrophic gastritis. Whereas serum PG I concentrations raised superficial gastritis,${ }^{14}$ they are markedly reduced in severe atrophic gastritis. ${ }^{6} 16$

Discriminate function analysis revealed that the PG I/PG II ratio, in combination with the absolute level of serum PG II, had a high sensitivity and predictive value for postoperative atrophic gastritis. The results require confirmation in other populations, but the available data indicate that in the postgastrectomy patient, as in the unoperated patient, ${ }^{6}$ serum PG I and PG II concentrations provide a 'serologic biopsy' of the gastric mucosa. It should be emphasised that the derived value of both determinations, the PG I/PG II ratio, has been found, in both postoperative and unoperated subjects, to be the key marker of gastric mucosal histology. It is evident from Figure 1A that the serum PG I concentration by itself is of little value in distinguishing among histologic groups. Although the data have not been presented, the same is true for the sum of the concentrations of PG I and PG II, which is the immmunochemical equivalent of the serum pepsinogen level that is obtained by conventional proteolytic assay.

Supported by Research Grant AM 32015 from the National Institutes of Health, Bethesda, Maryland, and by grants from the Sigrid Juselius Foundation, Helsinki, Finland.

\section{References}

1 Schrumpf E, Serck-Hansen A, Stadaas J, Aune S, Myren J, Osnes M. Mucosal changes in the gastric stump 20-25 years after partial gastrectomy. Lancet 1977, 2: 467-9.

2 Saukkonen M, Sipponen P, Varis K, Siurala M. Morphologic and dynamic behaviour of the gastric mucosa after partial gastrectomy with special reference to the gastroenterostomy area. Acta Hepatogastroenterol 1980; 27: 48-56.

3 Graem N, Fischer AB, Hastrup N, Poulsen CO. Muscosal changes of the Billroth II resected stomach. Acta Pathol Microbiol Scand Sect A 1981; 89: 227-34.

4 Janunger K-G, Domellof L, Eriksson S. The development of mucosal changes after gastric surgery for duodenal ulcer disease. Scand J Gastroenterol 1978; 13: 217-23.

5 Johnston DH. A biopsy study of the gastric mucosa in postoperative patients with and without marginal ulcer. Am J Gastroenterol 1966; 46: 103-10.

6 Samloff IM, Varis K, Ihamaki T, Siurala M, Rotter JI. Relationships among serum pepsinogen I, serum pepsinogen II and gastric mucosal histology. A study in relatives of patients with pernicious anemia. Gastroenterology 1982; 83: 204-9.

7 Samloff IM. Cellular localisation of group I pepsinogens in human gastric mucosa by immunofluorescence. Gastroenterology 1971; 61: 185-8.

8 Samloff IM, Liebman WM. Cellular localisation of the group II pepsinogens in human stomach and duodenum by immunofluorescence. Gastroenterology 1973; 65: 36-42.

9 Varis K, Marin-Sorenson M, Samloff IM, Weinstein WM. Immunocytochemical characterisation of pseudopyloric metaplasia. [Abstract] Gastroenterology 1983; 84: 1341.

10 Samloff IM. Pepsinogens I and II. Purification from gastric mucosa and radioimmunoassay in serum. Gastroenterology 1981; 82: 26-33.

11 Afifi AA, Azen SP. Statistical analysis. A computer oriented approach. New York: Academic Press, 1972.

12 Dixon WJ, Brown MB. BMDP-77, Biomedical computer programs $P$-series. Berkeley: University of California Press, 1977.

13 Spiro HM, Schwartz RDL. Superficial gastritis: A cause of temporary achlorhydria and hyperpepsinogenemia. $N$ Engl J Med 1958; 259: 682-4.

14 Ramsey EJ, Carey KV, Peterson WL et al. Epidemic gastritis with hypochlorhydria. Gastroenterology 1979; 76: $1449-57$.

15 Segal HL, Samloff IM. Tubeless gastric analysis techniques in diagnosis of chronic gastritis. JAMA 1966; 197: 717-8.

16 Varis K, Samloff IM, Ihamaki T, Siurala M. An appraisal of tests for severe atrophic gastritis in relatives of patients with pernicious anemia. Dig Dis Sci 1979; 24: 187-91. 